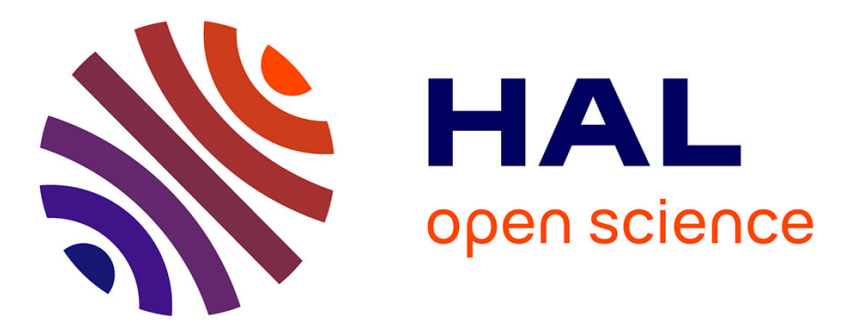

\title{
In situ analysis and modeling of crack initiation and propagation within model fretting contacts using polymer materials
}

Marie-Christine Baietto, Antoine Chateauminois, Bernard Villechaise

\section{To cite this version:}

Marie-Christine Baietto, Antoine Chateauminois, Bernard Villechaise. In situ analysis and modeling of crack initiation and propagation within model fretting contacts using polymer materials. Tribology International, 2003, 36 (2), pp.109-119. 10.1016/S0301-679X(02)00137-8 . hal-01951576

\author{
HAL Id: hal-01951576 \\ https://hal.science/hal-01951576
}

Submitted on 6 Jul 2021

HAL is a multi-disciplinary open access archive for the deposit and dissemination of scientific research documents, whether they are published or not. The documents may come from teaching and research institutions in France or abroad, or from public or private research centers.
L'archive ouverte pluridisciplinaire HAL, est destinée au dépôt et à la diffusion de documents scientifiques de niveau recherche, publiés ou non, émanant des établissements d'enseignement et de recherche français ou étrangers, des laboratoires publics ou privés. 


\title{
In situ analysis and modeling of crack initiation and propagation within model fretting contacts using polymer materials
}

\author{
M.C. Dubourg a,*, A. Chateauminois ${ }^{\mathrm{b}}$, B. Villechaise ${ }^{\mathrm{c}}$ \\ ${ }^{a}$ Laboratoire de Mécanique des Contacts, Insa de Lyon, UMR, Avenue A. Einstein, Villeurbanne Cedex 69619, France \\ ${ }^{\mathrm{b}}$ Laboratoire de Physico-Chimie Structurale et Macromoléculaire, ESPCI, UMR 7615, Paris, France \\ ${ }^{\mathrm{c}}$ Laboratoire de Mécanique des Solides, Université de Poitiers, UMR 6610, Futuroscope Chasseneuil, France
}

\begin{abstract}
Crack initiation and growth under fretting-fatigue and fretting-wear contact conditions have been investigated using model epoxy materials which allowed an in situ visualization of damage processes within the contact zone. A fretting-fatigue predictive model has been used to analyze these experiments on the basis of an accurate determination of the contact conditions and knowledge of the bulk fatigue properties of the epoxy materials. A special emphasis has been directed towards crack nucleation and early growth during Stage I and Stage I-to-Stage II transition, Stage II crack growth. Photoelastic experiments especially showed that crack propagation under fretting-fatigue loading was strongly dependent upon the complex cyclic micro-sliding behaviour of the crack faces. Under a fretting-wear condition, the constancy of the local contact conditions within the gross slip regime allowed the derivation of realistic estimates of the crack initiation times from the theoretical model.
\end{abstract}

Keywords: Fretting; Fatigue; Polymer; Nucleation; Propagation

\section{Introduction}

Fretting has long been recognized as a source of wear and premature fatigue failures within mechanical parts. Fretting damage may occur whenever a junction between contacting parts is subjected to cyclic sliding micromotions, whose characteristic amplitudes are much less than the size of the contact. Such a contact loading can be induced either by vibrations or by the application of bulk fatigue stresses to one or both of the contacting parts. Depending on whether the contact loading is induced by vibrations or bulk stresses, fretting is often termed fretting-wear or fretting-fatigue [1,2]. In the literature, the terms fretting-wear and fretting-fatigue were for a long time assimilated to the nature of the degradation. Accordingly, fretting-wear was considered to be essentially a wear problem, i.e. a loss of material, and fretting-fatigue a fatigue problem characterized by

\footnotetext{
* Corresponding author. Tel.: +33-4-72-43-84-49; fax: +33-4-7889-09-80.

E-mail addresses: marie-christine.dubourg@insa-lyon.fr (M.C. Dubourg); antoine.chateauminois@espci.fr (A. Chateauminois); bvillechaise@iutang.univ-poitiers.fr (B. Villechaise).
}

a drop in the fatigue limit. Numerous studies have, however, shown that wear and cracking processes often coexist within the same contact $[3,4]$. For example, extensive formation of debris was reported during fretting-fatigue tests, while no significant decrease in the fatigue limit was observed [5-7]. Hence, extremely different and even contradictory palliatives have been proposed due to this confusion between the nature of the contact loading and the associated damage $[8,9]$.

In order to capture the complexities of fretting damage, Godet, Vincent and Berthier have developed a different methodology based on both experimental and theoretical approaches. This approach relies on the design of well-controlled fretting devices [10], the third body approach [11] and the identification of the initial fretting damage [12] in terms of cracking or particle detachment. The influence of the many experimental parameters [13] has been rationalized by the introduction of fretting map concepts [4,14], which incorporate the materials and mechanical aspect of fretting damage. Two sets of fretting maps have been proposed (Fig. 1). The running condition fretting maps (RCFM) define, as a function of the normal load and the imposed relative displacement, different fretting regimes (partial slip, mixed 


\section{Nomenclature}

a contact semi-width (cylinder-on-flat) or contact radius (sphere-on-flat).

$f \quad$ frequency of the tangential loading

$P, Q \quad$ normal and tangential loads

$p_{\mathrm{m}} \quad$ average contact pressure

$R \quad$ radius of the sphere or cylinder counterface

$x \quad$ abscissa on the contact surface, $x=0$ corresponds to contact centre

$z \quad$ sample depth

$\alpha \quad$ angle of the crack initiation plane with respect to the normal to the specimen surface, i.e Stage I propagation plane

$\delta, \delta *$ instantaneous and maximum values of the relative tangential displacement

$\sigma \quad$ constant applied bulk load during the fretting static fatigue tests

$\sigma_{\mathrm{m}} \quad$ average value of the $n_{\mathrm{p}}$ discrete values of the normal stress, $\sigma_{\mathrm{n} n}$, calculated along the virtual crack plane

$\sigma_{\mathrm{m}, \max }$ average maximum normal stress

$\sigma_{\mathrm{m}, \min }$ average minimum normal stress

$\Delta \sigma_{\mathrm{m}} \quad\left(\sigma_{\mathrm{m}, \mathrm{max}}-\sigma_{\mathrm{m}, \mathrm{min}}\right) / 2$, average tensile stress amplitude

$\sigma_{\mathrm{a}} \quad\left(\sigma_{\mathrm{m}, \max }+\sigma_{\mathrm{m}, \min }\right) / 2$, average mean tensile stress

$\Delta \sigma_{\mathrm{m}}^{*} \quad$ average effective tensile stress amplitude

$\tau_{\mathrm{m}} \quad$ average value of the $n_{\mathrm{p}}$ discrete values of the shear stress, $\sigma_{\mathrm{nt}}$, calculated along the virtual crack plane

$\tau_{\mathrm{m}, \max }$ maximum value of the average shear stress

$\tau_{\mathrm{m}, \min }$ minimum value of the average shear stress

$\Delta \tau_{\mathrm{m}} \quad\left(\tau_{\mathrm{m}, \max }-\tau_{\mathrm{m}, \min }\right) / 2$, average shear stress amplitude

and gross slip regimes) which are defined by the nature of the local contact condition (i.e. partial slip or gross slip) and its changes as a function of the number of cycles. The main initial damage (cracking, particle detachment) is described separately in the so-called material response fretting maps (MRFM) for various combinations of normal load and relative displacement. These two sets of maps establish a close link between the main initial damage response and the nature of the contact conditions, which depends on the contact loading, the material's bulk mechanical properties and the frictional response of the contact interface [14,15]. The approach clearly demonstrates that the fretting resistance cannot be considered as an intrinsic property of a material, or even of a couple of materials, but that it is dependent on the evolving fretting regimes.

In the cracking domain of the MRFM, cracks may initiate at a very early stage and most of the component life incorporates crack growth. The cracks can induce surface spallation, they may self-arrest or they may grow up to the final failure of the component. The integration of such processes at the design stage in a predictive approach requires a multi-disciplinary phenomenological understanding which encompasses the interdependency of solid and contact mechanic, fatigue, material, wear and fretting mechanisms, and this from a local to a global scale of analysis. From a theoretical point of view, most of the work dedicated to fretting fatigue focused on the initiation process on the one hand and the continuous growth process on the other hand. These predictions are usually based on an estimate of the initial contact loading conditions. Some of the main difficulties inherent to fretting processes are, however, related to the evolving nature of the contact conditions. Within the different fretting regimes, the contact conditions may typically vary due to changes in the coefficient of friction or in the contact geometry as a result of particle detachment and third body accumulation and to the development of a cracks network. From an experimental point of view, the inability to localize, identify and monitor the nucleation and growth of cracks within a modified contact interface is certainly a factor impeding the development of reliable fretting models. Fretting experiments using macroscopic model contacts between polymers and rigid counterfaces have, however, emerged as a route to capture the complexities of fretting damage [1618]. In the context of cracking induced by fretting, the selection of appropriate brittle glassy polymers offers the possibility of performing a continuous in situ visualization of the crack development processes within the loaded contact zone. When associated with photoelastic devices, these experiments can also provide a convenient way of estimating the modified stress fields within a cracked contact in relation to the complex sliding behavior of the crack faces during the fretting cycle. The objective of this paper is to review the potential of such 
Runing Condition Fretting Maps (RCFM)

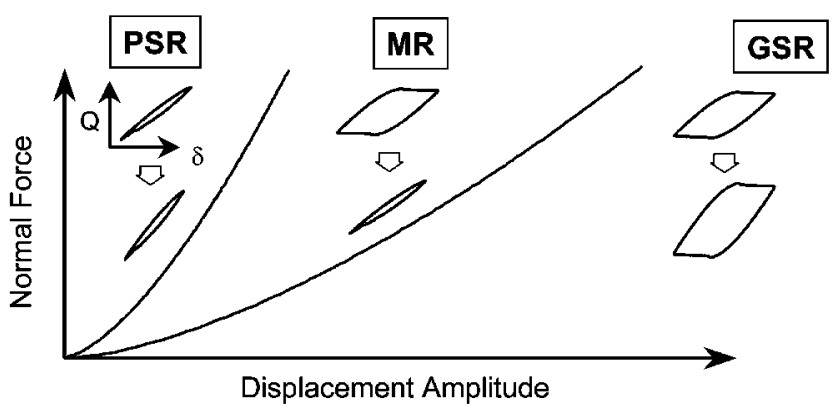

Material Response Fretting Map (MRFM)

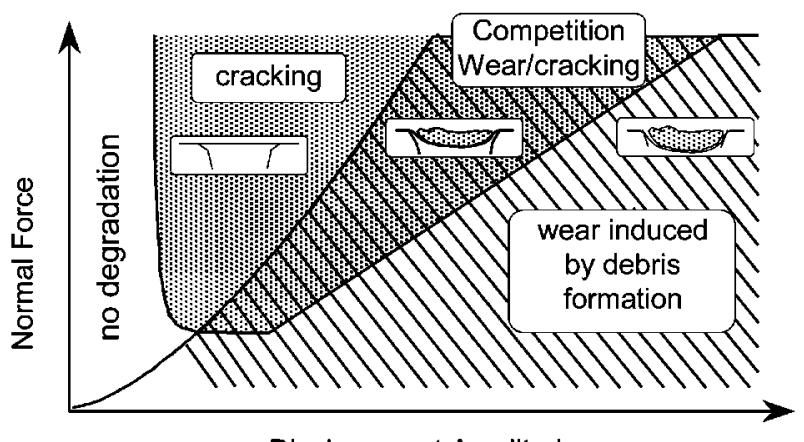

Displacement Amplitude

Fig. 1. Fretting maps concepts as introduced by Vincent et al. [4,14]. PSR: partial slip regime; MR: mixed regime; GSR: gross slip regime. The changes in the characteristic shapes of the fretting loops giving the tangential load, $Q$, as a function of the imposed relative displacement, $\delta$, are schematically described within the various regimes of the RCFM.

experimental approaches for the development and the validation of a theoretical fretting fatigue model.

\section{Fretting experiments}

Two kinds of fretting experiments have been considered. The first one corresponds basically to a frettingfatigue test, which allowed monitoring of the throughthickness propagation of cracks from side observations of a cylinder-on-flat photoelastic contact [16]. Using this device, qualitative and quantitative information on fretting crack initiation, location, inclination and growth rate were obtained together with continuous observations of the shear and/or tensile modes at the crack tip during the cyclic fretting loading. The second kind of experiments was based on fretting-wear loading [20]. In situ observation of the contact interface through a transparent glass counterface provided complementary data on the crack development processes in relation to the magnitude of the contact loading and the bulk fatigue properties of the polymer material.

\subsection{Polymer materials}

The selection of the polymer materials was dictated by two main requirements. First, the development of in situ visualization and photoelastic measurements imposed the use of transparent materials having suitable birefringence properties. Secondly, the analysis of the experimental data by means of an elastic contact model (see below) was relevant only for polymers with limited viscoelasticity at the test temperature and frequency. These various requirements were fulfilled by the choice of transparent epoxy polymers having glass transition temperatures above $100{ }^{\circ} \mathrm{C}$. Such epoxy materials are also known to be very sensitive to crack propagation under quasi-static and fatigue loading, which allowed us to obtain a damage response dominated by cracking under a wide range of fretting conditions.

For the fretting-fatigue tests, a commercially available photoelastic epoxy resin (PSM5, Vishay Micromesures, France) was used (cf. Table 1). The fretting-wear tests were carried out using an epoxy resin obtained by curing a stoichiometric amount of DGEBA monomer (LY 556, CIBA) with isophorone diamine (Hülls) as a hardener. At room temperature, the loss tangent, $\tan \delta=E^{\prime \prime} / E^{\prime}$, of the selected epoxy materials was found to be less than $5 \times 10^{-3}$ at $20^{\circ} \mathrm{C}$ from dynamic mechanical thermal analysis (DMTA) (Table 2).

\subsection{Fretting static fatigue tests}

Experimental data regarding crack location, orientation and propagation rates were obtained together with information on the contact conditions between crack faces using an experimental set-up combining the loading capability of a fretting- static fatigue device and a photoelastic system $[16,19]$. The contact consisted of a fixed aluminium alloy cylinder (radius $25 \mathrm{~mm}$ ) contacting a rectangular epoxy specimen ( $3 \times 40 \times 80 \mathrm{~mm}^{3}$ ) under a constant normal load, $P=$ $200 \mathrm{~N}$. The polymer specimen was subjected to (i) a static traction $\sigma$ and (ii) to an oscillating tangential displacement (Fig. 2a). The applied bulk stress was equal to $10 \mathrm{MPa}$. Depending on the magnitude of the tangential load, the measured tangential displacement varied between 0.5 and $0.7 \mathrm{~mm}$. The average contact width was equal to $1.5 \mathrm{~mm}$. In all the tests to be described, the frequency of the tangential loading was $f=10 \mathrm{~Hz}$.

The photoelastic system was composed of a light source and two polariscopes located perpendicularly to the lateral faces of the transparent epoxy material. The associated isochromatic fringe patterns were filmed using a charge coupled device (CCD) camera. A model was developed to analyze automatically the digitalized images [19]. It allowed dissociating and allocating the various fringes of the photoelastic pattern, the cracks being analyzed as single fringes. The model determined 
Table 1

Properties of the photoelastic epoxy system

\begin{tabular}{|c|c|c|c|c|}
\hline$E(\mathrm{GPa})$ & $v$ & $K_{\mathrm{IC}}\left[\mathrm{MPa}(\mathrm{m})^{1 / 2}\right]$ & $\begin{array}{l}\text { Photoelastic constant } \\
{[\mathrm{MPa} /(\text { Fringe/mm) }]}\end{array}$ & $T_{\alpha}\left({ }^{\circ} \mathrm{C}\right)$ \\
\hline 3.15 & 0.36 & $0.6-1.0$ & 10.7 & 115 \\
\hline
\end{tabular}

Table 2

Properties of the DGEBA/IPD epoxy resin

\begin{tabular}{lll}
\hline$E(\mathrm{GPa})$ & $\sigma_{\mathrm{y}}(\mathrm{MPa})$ & $T_{\alpha}\left({ }^{\circ} \mathrm{C}\right)$ \\
\hline 2.8 & 110 & 165 \\
\hline
\end{tabular}

$\sigma_{\mathrm{y}}$ : compressive yield stress measured at R.T. and $5 \times 10^{-4} \mathrm{~s}^{-1 ;} T_{\alpha}$ : glass transition temperature measured by dynamic mechanical thermal analysis (DMTA) from the maximum of the $\tan \delta$ peak at $1 \mathrm{~Hz}$ and $2{ }^{\circ} \mathrm{C} / \mathrm{min}$.

(a)

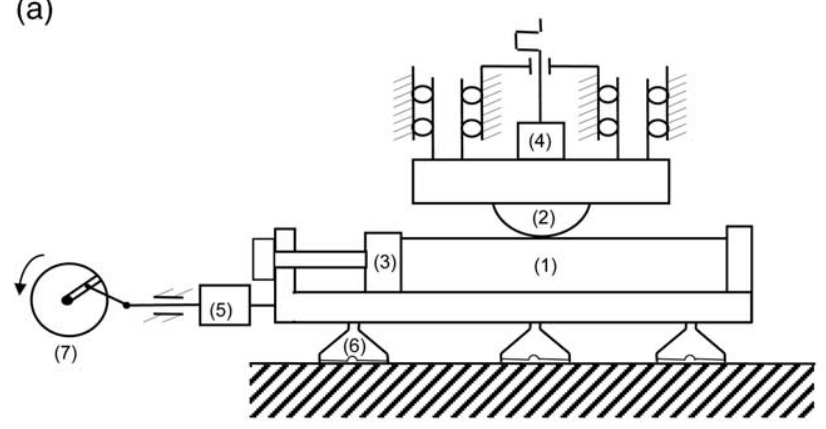

(b)

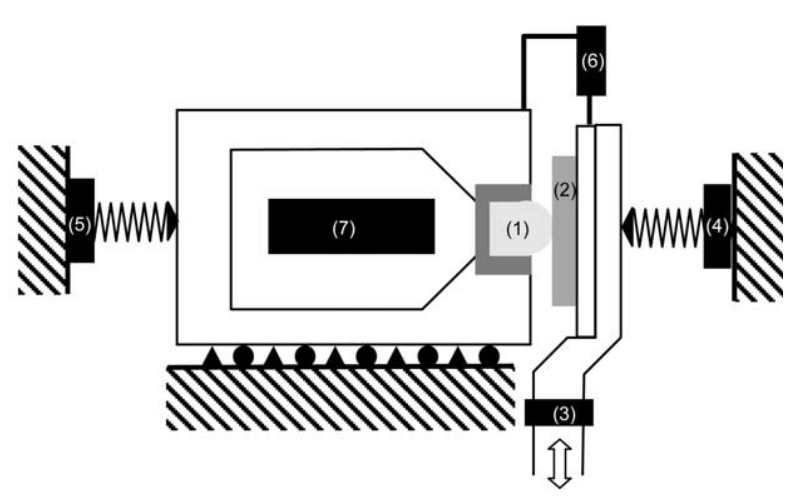

Fig. 2. Schematic description of the fretting tests. (a) Fretting static fatigue test: (1) epoxy specimen, (2) aluminium cylinder, (3) specimen tensile loading grip, (4) normal load transducer, (5) tangential load transducer, (6) air pads, (7) connecting rod and crank loading system. (b) Fretting wear test: (1) spherical glass counterface, (2) epoxy specimen, (3) tangential load transducer, $(4,5)$ normal load transducers, (6) extensometer, (7) microscope and CCD camera. the exact geometry and length of the cracks by providing the experimental constitutive crack points. Hence, the evolution of $\operatorname{crack}(\mathrm{s})$ (length, inclination) was recorded and both qualitative and quantitative data were obtained on the cracking phenomena (shear and/or tensile modes) and the stress field (through the isochromatic fringe patterns) generated during fretting fatigue cycles.

\subsection{Fretting-wear tests}

The fretting-wear tests were carried out using a modified tension-compression hydraulic device (Fig. 2b), which has been fully described elsewhere $[18,20]$. Flat epoxy specimens were rubbed against glass spherical caps (radius $R=48 \mathrm{~mm}$ ) under a constant applied normal load, $P=100 \mathrm{~N}$. An oscillating tangential displacement in the range from \pm 10 to $\pm 60 \mu \mathrm{m}$ was imposed on the contacting specimens. The frequency of the associated triangular shaped signal was set to $1 \mathrm{~Hz}$. During the fretting tests, the tangential load, $Q$, and the relative displacement, $\delta$, were continuously recorded in order to obtain fretting loops. The relative displacement was measured using a high precision extensometer located close to the contact in order to minimize the effects of machine compliance. These data were used as input in a real-time feedback loop which ensured the constancy of the amplitude of the imposed relative displacement thorough the test. In situ visualization of the contact interface was carried out through the glass counterface in a light transmission mode using a microscope device and a CCD camera. For the contact conditions under consideration, the measured diameter of the contact area was $2.1 \mathrm{~mm}$, which yielded an average contact pressure $p_{m}=32 \mathrm{MPa}$.

\section{Cracking model}

Many different methods and models have been proposed to deal with fretting cracks and to predict quantitatively the number of cycles to initiate a fatigue crack or the fatigue life. The main goals here are to identify the different and successive driving mechanisms which operate during the different stages that compose the lifetime, namely stage I and stage II. These two stages correspond respectively to the fatigue crack nucleation and 
early propagation through a zone close to the contact surface and to long crack propagation through the bulk of the specimen [21,22].

Crack nucleation and propagation processes were analyzed using a two-step procedure. The first step is devoted to the calculation of the continuum stress field within the epoxy specimen, either in the two-dimensional cylinder-plane or the three-dimensional sphereplane configuration within the frame of linear elasticity. The use of an elastic approach was justified in both cases $[19,20]$. The two contacting bodies are approximated by elastic half-spaces. The contact problem is then solved as a unilateral contact problem, using Coulomb's friction law. An incremental description of the loading is used to account for hysteretic phenomena.

The second step involves an analysis of the damage process, i.e. fatigue crack initiation during Stage I (location and orientation) and early propagation up to the Stage I-to-Stage II transition (branching depth and inclination). The damage processes occur initially within a zone close to the contact where the influence of the contact loading prevails on the applied bulk stresses. The associated stress field is multiaxial non-proportional and by essence confined within very small material volumes which are characterized by steep gradients. To deal with such complexities, it was proposed to develop an approach based on the averaging of the continuum macroscopic stress-strain fields along virtual crack planes orientated along various directions with respect to the contact plane $[22,23,24]$. On this basis, relevant mechanical parameters were proposed to predict the stage I cracking processes. Depending on the tensile or shear nature of the cracking process, two sets of parameters were introduced:

- $\left(\Delta \tau_{\mathrm{m}, \max }, \sigma_{\mathrm{a}} \approx 0\right)$ for a shear fatigue crack: these two specific parameters have been proposed to predict both the initiation site and a single growth direction. The growth occurs macroscopically in the direction given by the angle, $\alpha$, along which the value of the shear driving force, i.e. the amplitude of the average shear stress, $\Delta \tau_{\mathrm{m}}$, is maximum $\left(\Delta \tau_{\mathrm{m}}=\Delta \tau_{\mathrm{m}, \max }\right)$ and such that the mean value, $\sigma_{\mathrm{a}}$, of the average tensile stress, $\sigma_{\mathrm{m}}$, perpendicular to that direction, is minimum. The corresponding crack initiation domain is the zone where both conditions are fulfilled, assuming that the risk is the highest where $\sigma_{\mathrm{a}}$ is zero.

- $\left(\Delta \sigma_{\mathrm{m}, \max }^{*}, \Delta \tau_{\mathrm{m}, \min }\right)$ for a tensile fatigue crack. The propagation driving force is assumed to be the maximum amplitude of crack opening. The crack propagation angle, $\alpha$, is therefore defined by the direction along which the effective amplitude of the average stress normal to crack trajectory, $\Delta \sigma_{\mathrm{m}}^{*}$, is maximum $\left(\Delta \sigma_{\mathrm{m}}^{*}=\Delta \sigma_{\mathrm{m}, \max }^{*}\right) . \Delta \sigma_{\mathrm{m}}^{*}$ is defined as the amplitude of the positive values of the average tensile stress, $\sigma_{\mathrm{m}}$, which is assumed to be the driving force regarding the opening of tensile cracks. Furthermore, the amplitude of the average shear stress tends to a minimum value along that direction.

In the sphere-on-flat configuration, these parameters were determined in the contact meridian plane $y=0$ (Fig. 3) which corresponds to a plane of symmetry where the stresses are the highest and the cracks first initiate. The range of shear and tensile stresses for various contact locations within the sliding zone and for plane directions ranging from -90 to $90^{\circ}$ have been computed during the cyclic fretting loading. Average stresses were then computed along planes of length $L=20 \mu \mathrm{m}$.

The use of these parameters was initially justified from physical arguments based on the growth of dislocations from the surface of crystalline materials, such as aluminium alloys [23,25]. Although dislocations approaches have been proposed within the context of the deformation of glassy amorphous polymers [26], such concepts can obviously not be transposed to the contact fatigue behaviour of epoxies without a detailed investigation of the deformation processes at a microscopic scale. In this study, the above defined sets of mechanical parameters will thus be used essentially as tools to discriminate between predominant mode I or mode II crack propagation driving forces, without any underlying assumptions regarding the nature of the microscopic processes involved in crack initiation. It was, however, expected that the adequacy, or the inadequacy, of the approach to describe contact cracking processes could provide some indication on the relative contributions of the mechanical loading and the microstructural factors.

\section{Three dimensional contact analysis}
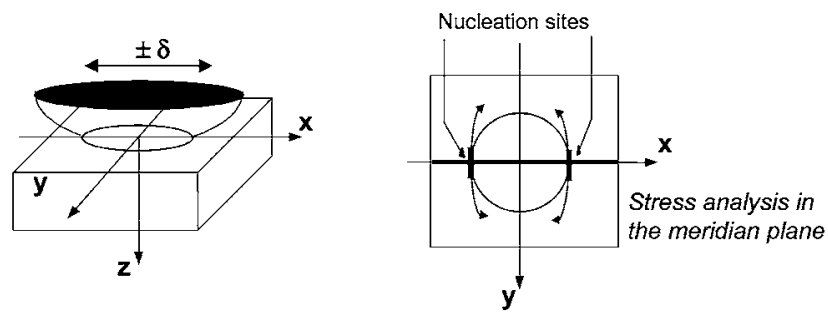

Theoretical approach to initial crack growth
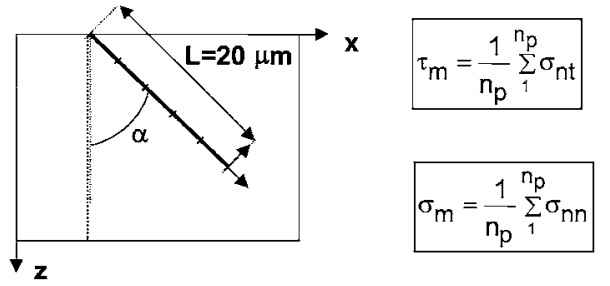

Average shear stress

Fig. 3. Theoretical approach to crack analysis within the contact meridian plane. 

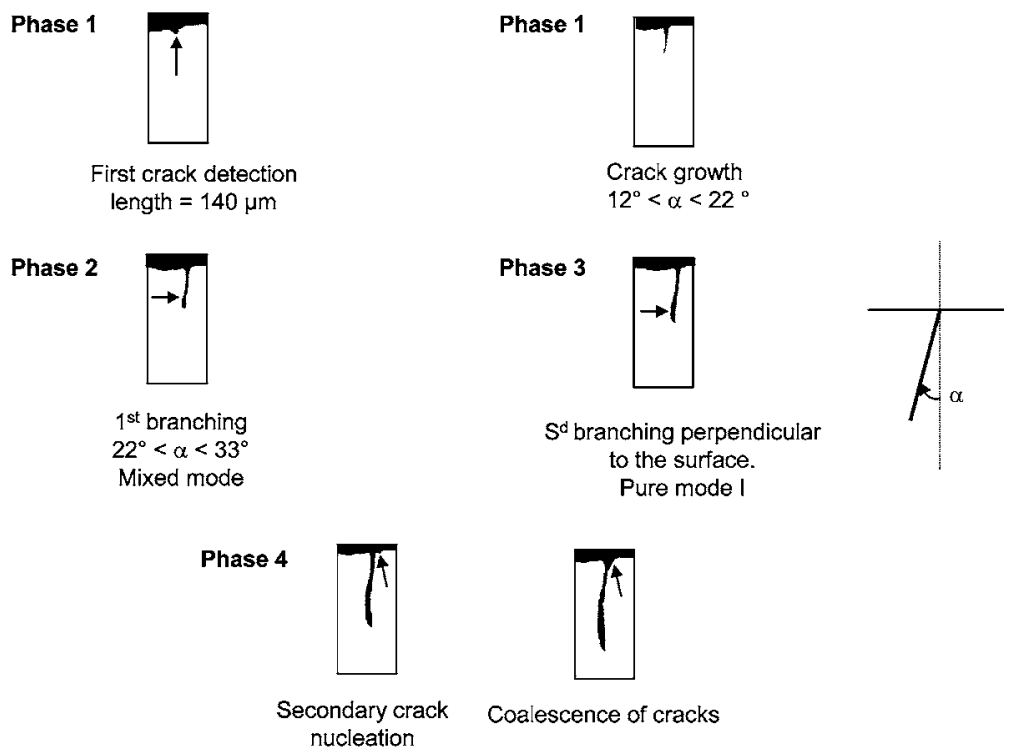

Fig. 4. Photographs showing the various stages of crack propagation under fretting static fatigue conditions (cylinder-on-flat configuration, observation on the lateral face of the epoxy specimen) [16].

\section{Experimental observations}

\subsection{Crack directions and propagation rates under fretting-static fatigue loading}

Fretting-static fatigue tests have been carried out within the partial slip regime. Under such conditions, the first detectable cracks (about $150 \mu \mathrm{m}$ in length) were observed at the boundary between the central adhesive zone and the micro-sliding area. The subsequent crack growth involved typically five successive phases, which were characterized by different crack orientation (Fig. 4) and/or propagation rates (Fig. 5):

Phase 1. The crack grows at an increasing rate up to a length of about $900 \mu \mathrm{m}$ and along a direction ranging from 12 to $23^{\circ}$ with respect to the normal to the surface. Phase 2. A first crack branching mechanism is observed

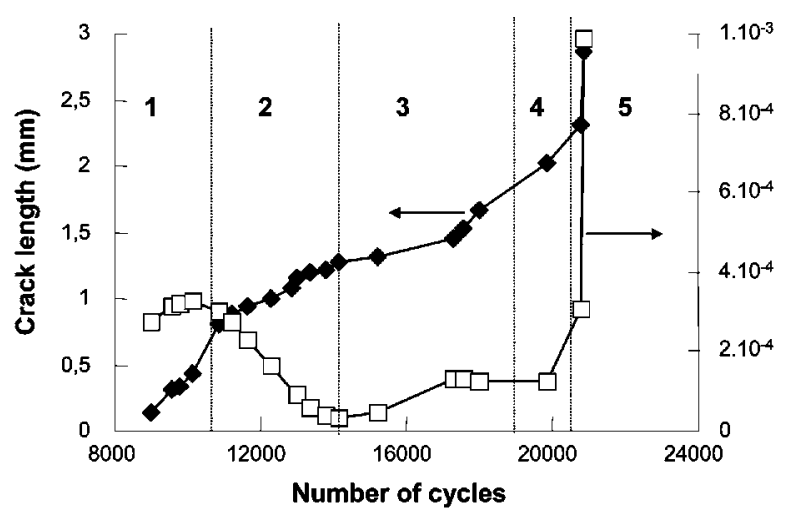

Fig. 5. Crack length and propagation rates as a function of the number of cycles during a fretting static fatigue test [16]. at an angle varying from 22 to $37^{\circ}$. During this stage, the propagation rate decreases as the crack is growing out of the contact zone.

Phase 3. At about $1.3 \mathrm{~mm}$ from the surface, a crack reorientation along a direction normal to the surface is observed.

Phases 4 and 5. These correspond to the final propagation stages up to the specimen failure. During these phases secondary crack nucleation and crack coalescence mechanisms may be observed.

A better understanding of the contribution of (i) the cyclic contact stresses and (ii) the bulk stress during fatigue life was provided by the continuous visualization of the isochromatic stress field and the movements of the crack faces (sliding and opening processes). It highlighted particularly the key role of the contact stresses during phase 3 , although the crack has grown up to a depth of the same order of magnitude as the contact size. As mentioned above, phase 3 is characterized by a crack branching perpendicular to the surface and obviously perpendicularly to the static bulk stress. Nevertheless, crack propagation was only possible through the additional contribution of the driving forces arising from the contact loading. The analysis of the isochromatic fringe patterns (Fig. 6) demonstrated that the latter involved the complex micro-sliding behaviour of the two contacting crack faces. During the fretting cycle, the occurrence of sliding micro-motions along the second crack segment was especially found to result in a cyclic opening of the crack tip which was superimposed on the constant crack opening associated with the static tensile stresses. 
(a)

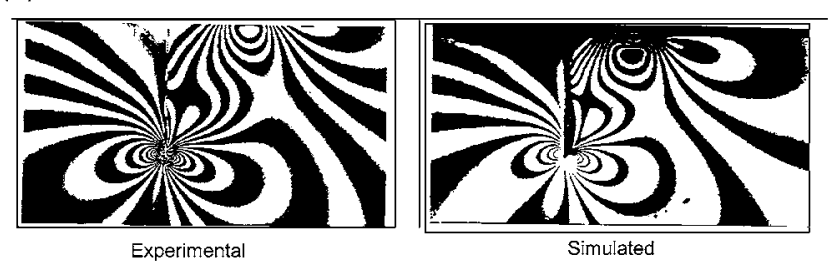

(b)

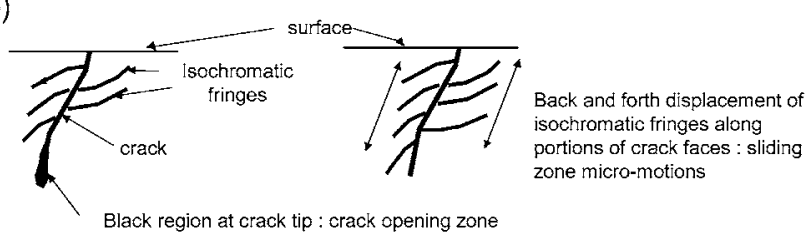

Fig. 6. Development of isochromatic fringe patterns within a cracked epoxy body under fretting static fatigue. (a) Experimental and calculated isochromatic stress fields (isovalues of $\tau_{\max }$ ); (b) schematic description of the crack behaviour as deduced from the observation of the isochromatic fringes.

\subsection{Analysis of the cracking behaviour within the fretting regimes}

A typical example of the initial development of a contact fatigue crack network under fretting-wear loading is shown in Fig. 7. This experiment was carried out using an imposed displacement amplitude $\left(\delta^{*}= \pm 60 \mu \mathrm{m}\right)$ which ensured the development of a gross slip contact condition during the entire fretting test, i.e. within the gross slip regime of the RCFM. Crack initiation and propagation processes were detected on the surface of the epoxy material by means of in situ visualization. In addition, the continuous monitoring of the contact tangential stiffness also provided some qualitative information regarding the propagation of the cracks through the depth of the epoxy substrate. After about 300 fretting cycles, two cracks were detected close to the edge of the contact at two approximately symmetrical locations along the sliding direction. The final propagation of these cracks occurred within a few tens of cycles, in a quasi-brittle manner, as indicated by the optical observations and the rapid decrease in the measured contact stiffness. As the number of cycles was increased, secondary cracks developed close to the initial cracks, but they resulted in a more limited and progressive decrease in contact stiffness.

Crack initiation times and depths have been investigated as a function of displacement amplitude within the various regimes of the RCFM. The three following damage domains can be identified as the magnitude of the imposed displacement is increased (Fig. 8). First, a noncracking domain (I) where no crack is nucleated after $5 \times 10^{4}$ fretting cycles. Secondly, a domain (II) where the number of cycles to crack nucleation and the propagation depths decrease and increase progressively, respectively, as the magnitude of the tangential loading is increased. In the last domain (III), crack propagation occurs within a few fretting cycles after an initiation time of about 400 cycles, with no significant dependence on the magnitude imposed displacement. Within this last

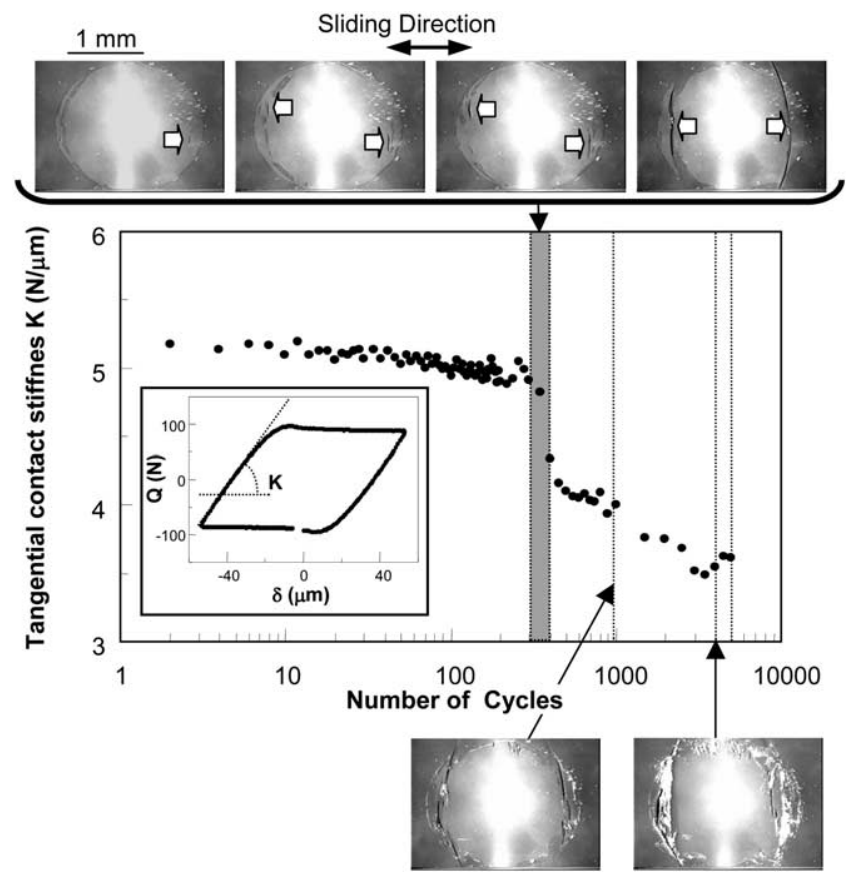

Fig. 7. Crack initiation and propagation within the gross slip regime (fretting wear loading). Pictures were obtained from in situ observation of the contact area. The white arrows indicate the location of cracks. Insert: determination of the tangential contact stiffness, $K$, from the experimental fretting loops. 

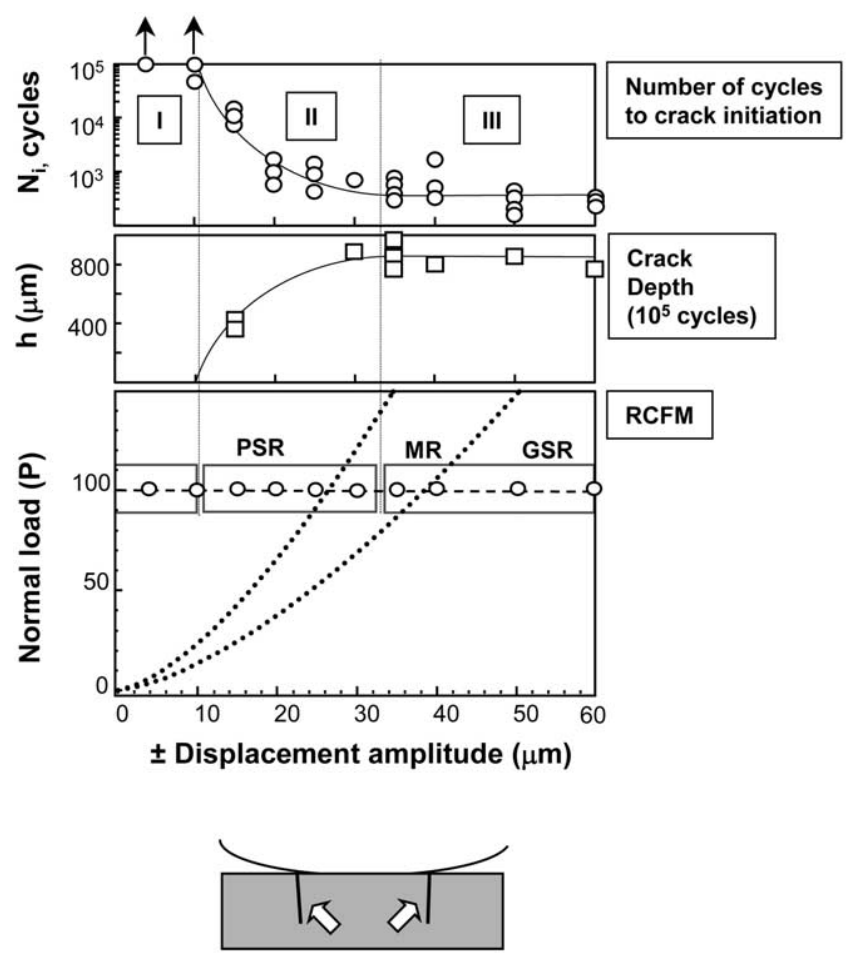

Fig. 8. Number of cycles to crack initiation, $N_{\mathrm{i}}$, and crack depths, $h$, within the various regimes of the RCFM under a fretting wear loading (see text for comments on regions I, II and III).

domain, the crack depths are of the same order of magnitude as the radius of the contact area.

As indicated in Fig. 8, domain I corresponds to the low displacement range of the partial slip regime, domain II overlaps the mixed slip regime and a portion of the partial slip regime and domain III is associated to the gross slip regime. Contrary to what is usually reported for metallic materials, no significant particle detachment was observed within the gross slip regime where cracking remains the main initial material response in terms of damage. The very low roughness of the contacting surfaces (in the order of a few nanometers) can probably account for this difference. Another explanation is also related to the early propagation of the two deep cracks at the contact edge, which strongly modify the velocity accommodation mechanisms. During the fretting cycle, a significant part of the imposed displacement can be accommodated within the cracked epoxy body by the alternate opening and closing of the cracks. As a result, the magnitude of the actual slip induced at the contact interface is reduced and this may in turn reduce the particle detachment processes.

\section{Prediction of initial cracking processes under a fretting wear condition}

The analyses introduced in this paper are directed towards a better understanding of the fretting resistance in terms of the resistance to crack growth. The main step in the fretting damage prediction is, at first, to identify the different and successive fatigue driving mechanisms which operate during the different stages that compose the lifetime, i.e. Stage I (crack initiation sites and direction), Stage I-to-Stage II transition (depth of branching, direction) and Stage II growth. Regarding Stage I under fretting-wear condition, all the necessary conditions for the analysis of crack initiation using the elastic cracking model are a priori fulfilled:

- Within the three regimes of the RCFM, no significant modification of the contact geometry due to particle detachment and/or third body accumulation was observed. The initial cracking processes under investigation therefore occur within an essentially twobody contact, the geometry for which is dictated by the Hertzian normal loading. Such a situation is consistent with the boundary conditions imposed during the numerical simulations.

- At least within the gross slip regime, the changes in the magnitude of the tangential loading can be monitored unambiguously from the continuous measurement of the coefficient of friction. The experimental difficulties associated with the determination of the extent of the micro-slip zone under partial slip conditions (see below) are especially avoided. Although an initial increase of the coefficient of friction was systematically noticed within the gross slip regime, it occurred within a short period as compared with the number of cycles to crack initiation [20]. As a result, the intensity of the tangential loading can to a first approach be considered as constant during the whole fretting test, which is one of the prerequisites for the use of constant amplitude bulk fatigue data for the analysis of contact cracking.

In order to predict the initial crack orientation, the values of $\Delta \tau_{\mathrm{m}, \max }$ and $\Delta \sigma_{\mathrm{m}, \max }^{*}$ were calculated as a function of the segment orientation and the location within the contact during the various steps of a discrete tangential loading. Due to the loading symmetry and for the sake of clarity, only the results corresponding to one half of the contact have been represented in Fig. 9. It can be noted that the maximum value of $\Delta \sigma_{\mathrm{m}, \max }^{*}$ is achieved at the edge of the contact for an angle of $7^{\circ}$, which is very close to the average experimental crack orientation $\left(11^{\circ}\right)$. Along the same plane, the shear amplitude is also minimized (Fig. 10). The simulation therefore clearly establishes that the initial cracks that nucleated close to the contact edge correspond to mode I tensile fatigue cracks.

Accordingly, the contact fatigue data may be compared to the bulk fatigue data of the epoxy polymer, provided that the latter are obtained under loading conditions yielding predominantly mode I crack opening. This was indeed the case under a three-point bending 


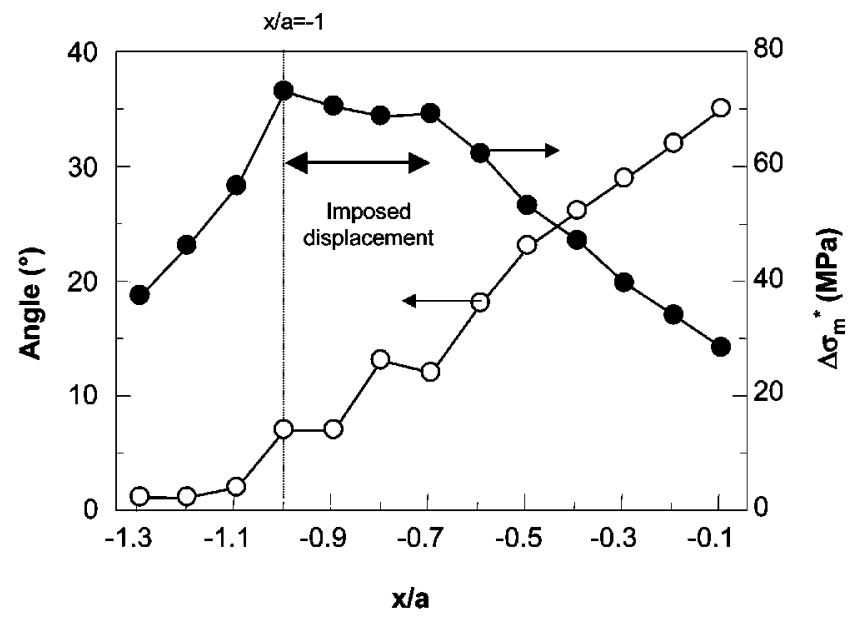

Fig. 9. Changes in the average effective tensile stress, $\Delta \sigma_{\mathrm{m}}^{*}$, and in the orientation of the corresponding crack plane as a function of the location within the contact area ( $a$ is the radius of the contact area).

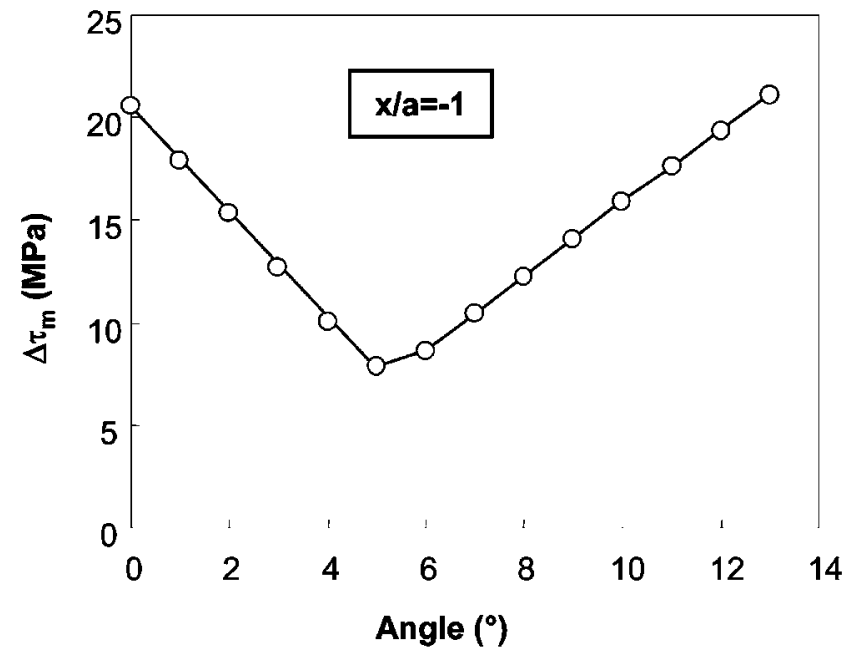

Fig. 10. Values of the maximum amplitude of the shear stress, $\Delta \tau_{\mathrm{m}}$, as a function of the orientation for $x / a=-1$ (contact edge).

condition, where the cracks were found to initiate and propagate on the tensile side of the specimens. Moreover, a monitoring of the bending stiffness indicated that the crack propagation step represented a very limited fraction of the flexural lifetime. Accordingly, the measured lifetimes under three-point bending conditions may, to a first approximation, be assimilated to the crack initiation times.

Within the gross slip regime, the simulation indicated that the effective amplitude of the average tensile stress normal to the crack plane is about $70 \mathrm{MPa}$. When reported in the fatigue diagram of the bulk epoxy resin (Fig. 11), this value yield a lifetime (about 250 cycles) which is very close to the observed crack initiation time within the contact. Although the fatigue conditions were different for the two kinds of loading $(R=0.1 ; F=$ $10 \mathrm{~Hz}$ for three-point bending fatigue tests; $R=-1.2$ and $F=1 \mathrm{~Hz}$ for fretting-wear tests), these results tend

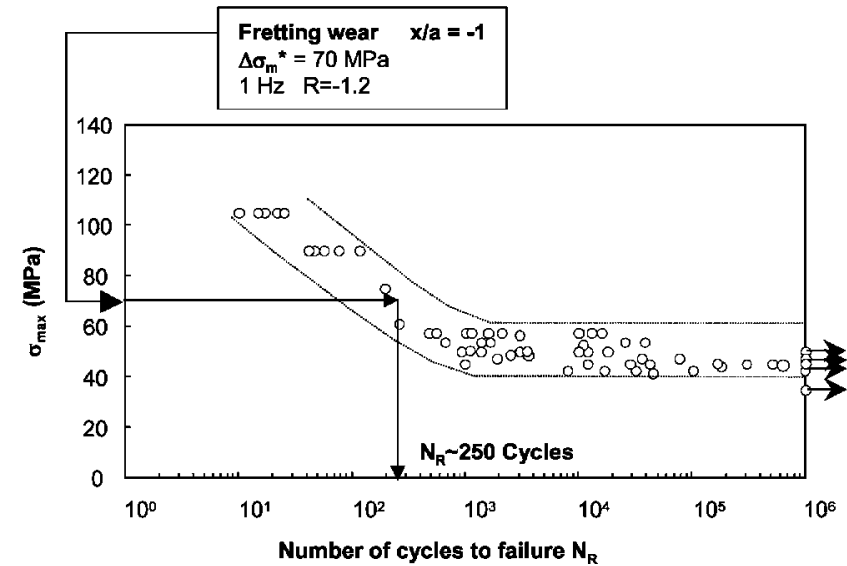

Fig. 11. S-N data of the bulk DGEBA/IPD epoxy resin under three point bending conditions $(R=0.1,10 \mathrm{~Hz})$.

to demonstrate that, for the glass/polymer contact under investigation, the use of bulk fatigue data is relevant to contact fatigue prediction. Accordingly, the boundary of domain I could be assimilated to the endurance limit of the bulk epoxy.

From a more general point of view, it must be emphasized that such an approach can only be applied to fretting contacts which are characterized by quasiconstant fretting loading conditions, i.e. when the evolution of the topography of the fretted surface together with the variation of the frictional force, among others factors, are negligible. In this context, cracking is the dominant damage response throughout the whole fatigue life. The life prediction may be performed successfully and data coming from $\mathrm{S}-\mathrm{N}$ curves established for uniaxial plain fatigue or equibiaxial fatigue may be used directly. Some authors have proposed a fretting life reduction factor or a fretting fatigue strength reduction factor (FFSRF) obtained from the comparison of Wöhler curves obtained from specific experimental setups with 
and without fretting. When cracking is the dominant damage mechanism concomitantly with a limited wear damage throughout the fatigue life, FFSRF may be of some help in ranking, in a certain manner, the susceptibility of different contacting combinations to fretting fatigue [27].

The analysis may, however, be largely complicated when changes in the contact loading conditions are encountered during the course of the fretting process. Such non-constant fretting loading conditions encompass the following situations:

(i) The interface friction is evolving but the contact geometry remains essentially unchanged. Within the gross slip regime, these effects could be incorporated within a nonlinear cumulative model using variable amplitude fatigue data and the experimental variations of the coefficient of friction as a function of the number of cycles. Within the partial slip and the mixed regimes, such an approach would require knowledge of the changes in the local coefficient of friction within the partial slip zone, together with the assessment of the distribution of partial slip and adhesive zones within the contact. As mentioned above, this latter point is essential in order to determine the boundary conditions for the numerical simulations of the contact problem. Within the context of metallic contact, it has been shown that inverse approaches based on the analysis of the experimental fretting loops in the light of Mindlin's analysis could provide some realistic values of the local coefficient of friction under partial slip condition $[28,29]$. A detailed examination of epoxy/glass fretting contacts showed, however, that these approaches could fail when friction induced microstructural modifications result in strong deviations from the theoretical Mindlin's description [20]. This later complication introduces a major difficulty in the mechanical analysis of the cracking behaviour within domain II. From an experimental point of view, one of the challenges is certainly the development of in situ observation techniques, allowing the precise determination of the changes in the boundary between adhesive and micro-slip zones within the partial slip and mixed regimes.

(ii) If cracking competes with wear processes and/or third body accumulation, the prediction of crack nucleation is more difficult: the evolution of the topography of the fretted surfaces together with the variation of the frictional force change the initial cyclic multiaxial stress-strain field into a non-constant cyclic multiaxial stress-strain field. As a result, the average maximum shear stress and the average effective normal stress amplitudes may occur at different locations and along different orientations, which modifies the resulting fatigue processes.

\section{Conclusion}

The replacement of aluminum alloys by amorphous polymers to investigate cracking phenomena under fretting fatigue loading addressed the problem of the influence of material microstructure on crack nucleation and propagation processes. At the scale of observation, the adequacy of the cracking model to describe the observed epoxy behaviour tends to demonstrate that the effects of material microstructure were minimized; the effects of the mechanical stress-strain state were prevailing on microstructural effects. This means that (i) the microstructural thresholds affecting the initiation stages [3033 ] were already passed and (ii) the crack response was dictated by the mixed mode and the second pure mode I threshold. This conclusion is further reinforced by the similarities observed in cracking behavior (location, orientation) between the aluminum and the epoxy tests [24].

The theoretical approach developed for fretting crack prediction is based on continuum mechanics coupled with contact mechanics. An averaging method has been proposed to evaluate the range of shear and tensile stresses for all material locations and for all possible plane directions during the cyclic fretting loading. Using this approach, the crack nucleation and early growth processes have been analyzed for various local fretting conditions. It should be pointed out that, provided cracking remains the dominant damage during the fretting lifetime, crack nucleation (location, orientation, initiation times) can be predicted successfully from bulk fatigue data. The formation of macroscopic cracks and their influence on the stress and strain fields have also been accounted for in the photoelastic analysis of the fatigue crack process during Stage II growth. These observations clearly demonstrate that the complex micro-sliding behaviour along the crack faces affects the complex stress state at the crack tip and the resulting crack propagation rates (Table 2).

\section{References}

[1] Waterhouse RB. Fretting corrosion. Oxford: Pergamon, 1972.

[2] Waterhouse RB. Fretting fatigue. Applied Science, London: Elsevier, 1981.

[3] Vingsbo O, Soderberg D. On fretting maps. Wear 1988;126:131-47.

[4] Vincent L, Berthier Y, Dubourg MC, Godet M. Mechanics and materials in fretting. Wear 1992;153:135-48.

[5] Hoeppner DW, Gloss DL. Metallographic analysis of fretting fatigue damage in Ti 6Al4VMA and 7075-T6 aluminium. Wear 1989;62:287-97.

[6] Bill RC. Fretting wear and fretting fatigue-how are they related? ASME J Lub Tech 1981;13:1-9.

[7] Wharton MH, Waterhouse RB. Environmental effects in the fretting fatigue of TiAl4V. Wear, 62 1980;6:287-97.

[8] Beard J. An investigation into the mechanisms of fretting fatigue. $\mathrm{PhD}$ dissertation, University of Salford (UK); 1982. 
[9] Gordelier S-C, Chivers T-C. A literature review of palliatives for fretting fatigue. Wear 1979;56:177-90.

[10] Vincent L, Berthier Y, Godet M. Testing methods in fretting fatigue: a critical appraisal. In: Attia MH, Waterhouse RB, editors. Standardization of fretting fatigue test methods and equipment, ASTM-STP 1159. Philadelphia (PA): American Society for Testing and Materials; 1992. p. 33-48.

[11] Godet M. The third body approach: a mechanical view of wear. Wear 1984;100:437-52.

[12] Berthier Y, Vincent L, Godet M. Fretting fatigue and fretting wear. Tribol Int 1989;22(4):235-42.

[13] Dobromirski JM. Variables of fretting process: are they 50 of them? In: Attia MH, Waterhouse RB, editors. Standardization of fretting fatigue test methods and equipment, ASTM STP 1159. Philadelphia (PA): American Society for Testing and Materials; 1992. p. 60-6.

[14] Fouvry S, Kapsa P, Vincent L. Quantification of fretting damage. Wear 1996;200:186-205.

[15] Zhou ZR, Vincent L. Effect of external loading on maps of aluminium alloys. Wear 1993;619-623:162-4.

[16] Lamacq V, Dubourg M. Fretting fatigue crack growth analysis. Experimental photoelastic method combined with numerical method. In: ECF 11, Mechanisms and mechanics of damage and failure. 1996. p. 1387-92.

[17] Dubourg M, Mouwakeh M, Villechaise B, Godet M. Crack behaviour under cyclic loading. In: Dowson D, Taylor C-M, Godet M, Berthe D, editors. Interface dynamics, Tribology series 12, Proceedings of the 14th Leeds-Lyon Symposium, Lyon; 1987 Sep 8-11. Amsterdam: Elsevier; 1988. p. 41-8.

[18] Chateauminois A, Kharrat M, Krichen A. Analysis of fretting damage in polymers by means of fretting maps. In: Hoeppner DW, Chandrasekaran V, Elliott CB, editors. Fretting fatigue: current technology and practices, ASTM STP 1367. West Conshohocken (PA): American Society for Testing and Materials; 2000. p. $352-66$.

[19] Lamacq V. PhD thesis, INSA; 1997, 251 pp. (in French).

[20] Kharrat M, Krichen A, Chateauminois A. Analysis of the local loading conditions in an epoxy/glass contact under fretting loading. TribolTrans 1999;42(2):377-84.

[21] Forsyth PJE. A two-stage process of fatigue crack growth. In: Symposium on Crack Propagation, Cranfield. London: HMSO; 1971. p. 76-94.

[22] Lamacq V, Dubourg M-C. Modeling of initial fatigue crack growth and crack branching under fretting conditions. Fatigue Engng Mater Struct 1999;22:535-42.

[23] Reybet Degat P, Lamacq V, Dubourg MC, Zhou ZR, Vincent L. Experimental and theoretical approach to fretting crack nucleation on pre-stressed aluminum alloy. In: ECF 11, Mechanisms and mechanics of damage and failure. 1996. p. 1443-5.

[24] Lamacq V, Dubourg M-C, Vincent L. A theoretical model for the prediction of initial growth angle and sites of fretting fatigue cracks. Tribol Int 1997;30(6):391-400.

[25] Reybet Degat P, Zhou ZR, Vincent L. Fretting behavior on prestressed aluminum alloy specimen. Tribol Int 1996;30(3):711-20.

[26] Perez J. Physics and mechanics of amorphous polymers. Lavoisier, 1998.

[27] Giannakopoulos AE, Lindley TC, Suresh S. Applications of fracture mechanics in fretting fatigue assessment, ASTM STP 1367 2000. p. 80-99.

[28] Tonck A, Kapsa P, Sabot J. Mechanical behaviour of tribochemical films under a cyclic tangential load in a ball-flat contact. ASME J Trib 1986;108:117-22.

[29] Hills DA, Nowell D. In: Mechanics of fretting fatigue, ch. 5. London: Kluwer Academic Publishers; 1994.

[30] Miller KJM. aterials science perspective of metal fatigue resistance. Mater Sci Technol 1993;9:453-62.

[31] Miller KJ. The two thresholds of fatigue behaviour. Fatigue Fract Engng Mater Struct 1993;16:931-9.

[32] Miller KJ. The three thresholds for fatigue crack propagation. In: 27th Conference on Fatigue and fracture Mechanics, ASTM STP 1296; 1997. p. 267-86.

[33] Brown MW. Interfaces between short, long and non-propagating cracks. In: Miller KJ, de los Rios ER, editors. The behaviour of short fatigue cracks, EGF Pubication 1. London: MEP Institution Mechanical Engineers, 1986. p. 423-39. 